\title{
EFFICACY OF TWO NI-TI RETREATMENT SYSTEMS AND HAND FILES IN REMOVING GUTTA-PERCHA AND SEALER FROM ROOT CANALS FILLED WITH THREE DIFFERENT TYPES OF SEALERS
}

Rajender Singh $^{1}$, Ashu Gupta ${ }^{2}$, Vishal Sharma ${ }^{3}$

${ }^{1}$ Jr. Resident, Department of Conservative Dentistry \& Endodontics, Govt. Dental College \& Hospital, Himachal Pradesh, India ${ }^{2}$ Professor \& Head, Department of Conservative Dentistry \& Endodontics, Govt. Dental College \& Hospital, Himachal Pradesh, India ${ }^{3}$ Assistant Professor, Department of Conservative Dentistry \& Endodontics, Govt. Dental College \& Hospital, Himachal Pradesh, India

\begin{abstract}
Objectives: This study was undertaken to evaluate the efficiency of two rotary nickel titanium instruments and hand instrumentation in removing gutta-percha and sealer from root canals. Study design: 63 extracted human single rooted premolars were instrumented with K-files and filled using lateral compaction of guttapercha (GP) and three different sealers. The teeth were randomly divided into three experimental groups of 21 specimens each. Removal of gutta-percha was performed with R-Endo retreatment files, Mtwo retreatment files and Hedstrom files. Time to reach working length and to eliminate filling material was also recorded. The specimens were sectioned for evaluation of the area of the remaining gutta-percha/sealer under stereomicroscope at 6X magnification. Photographs were taken for further analysis using computer image analysis program. The results were statistically analyzed using Analysis of variance (ANOVA) and Tukey's honestly significant difference test. Results: The R-Endo retreatment system resulted in a smaller percentage of canal area covered by residual GP/sealer than in other groups, a significant difference was found between R-Endo and Mtwo group and between Hedstrom groups $(\mathrm{P}<0.001)$. The Mean operating time was minimum with R-Endo group while it was found to be maximum with hand files. Conclusion: It was concluded that all test techniques left gutta-percha/sealer remnants within the root canal. The R-Endo retreatment files and Mtwo retreatment files system proved to be an efficient method for removing gutta-percha and sealer from single rooted premolars.
\end{abstract}

Keywords: Gutta-percha, Root Canal Sealer, Rotary Instruments.

\section{INTRODUCTION}

After a root canal procedure, a tooth may require retreatment because of a persistent infection or reinfection of the root canal. Retreatment requires complete removal of the root canal filling material, followed by further shaping, cleaning and re-obturation. ${ }^{1,2}$ Many of these cases can be managed successfully and the tooth saved by careful endodontic retreatment.

Post-treatment disease is associated with the persistence of microorganisms in the root canal system after cleaning and shaping or with the recolonization of the root canal space by bacteria following coronal or apical microleakage (Nair et al. 1990). E-mail: poonsood@gmail.com Received: $26^{\text {th }}$ April 2015 Accepted:29 July 2015 Online: $10^{\text {th }}$ September 2015
Although root canal treatment has a variable success that varies from $86 \%$ and $98 \%,{ }^{5}$ which may be due to a number of biological and technical factors such as untreated canals ${ }^{6}$, perforations, inadequately filled canals ${ }^{7}$ or coronal leakage, there by periapical tissues causing periradicular lesions.

The primary goal of root canal retreatment is to treat the infectious process through the removal of filling material, debris, and microorganisms that cause apical periodontitis ${ }^{8,9}$ One of the basic properties of the ideal root canal filling technique and material is that it should be removable whenever necessary for retreatment purposes. ${ }^{10}$

For proper removal of the guttapercha obturating material, many techniques and materials have been used in root canal-treated teeth. Many techniques have been proposed for removing root filling materials like 
rotary nickel-titanium (NiTi) instruments ${ }^{11}$, ultrasonic instruments, ${ }^{12}$ heat pluggers ${ }^{13}$, and manual instruments with chemical solvents (chloroform, eucalyptol, orange oil). ${ }^{14}$

Rotary Ni-Ti instruments have proved to be effective 14 and time-saving 15 in removing filling materials. However, none of the several treatment alternatives seem to guarantee canal walls that are completely free of debris. ${ }^{16}$ Several retreatment techniques, such as the use of nickel-titanium rotary instruments, have been proposed..$^{17,18,19}$ These instruments are more efficient than hand instrumentation; they reduce clinician's time operator as well as patient fatigue. ${ }^{20}$ However, none of these techniques are totally effective in removing filling material. $^{21-22}$

Several nickel-titanium retreatment rotary systems with different features have been developed to improve efficiency and retreatment success rates. In order to improve safety preparation and to prepare more appropriate shapes, advanced instrument designs with non cutting tips, radial lands, varying tapers, rake angles and changing pitch lengths have been developed. $^{23}$

The R-Endo retreatment files comprise of 3 files as R1 (15 mm, 25/.08), R2 (19 mm, 25/.06), and R3 (23 $\mathrm{mm}, 25 / .04)$ and are used at coronal, middle, and apical thirds, respectively.

Mtwo R (retreatment) files consist of 2 files (15/.05 and 25/.05). These files have an active tip, and when WL is reached, the preparation continues with Mtwo rotary NiTi system.

An H-type instrument has a spiral edge arranged to allow cutting only during a pulling stroke. An important method to remove gutta percha, especially when the canal has been overextended vertically and under filled laterally, is to utilize the Hedström displacement technique.

Sealers are used between dentin surfaces and core materials to fill spaces that are created due to the physical inability of the core materials to fill all areas of the canal. Traditionally desirable characteristics were to adhere to dentin and the core material as well as to have adequate cohesive strength. Newer generation sealers are being engineered to improve their ability to penetrate into dentinal tubules and bond to, instead of just adhering to, both the dentin and core material surfaces. In this study we used either of three sealers which include ZOE, AH Plus and EndoRez as the obturating materials.

\section{MATERIALS AND METHOD}

\section{Sample Preparation:}

Sixty-three extracted human pre-molar teeth of similar length were selected. Inclusion criteria were absence of a root canal filling, presence of a single patent root canal, complete formation of the apex and no caries or fracture in a tooth. Soft tissues and calculus were mechanically removed from the root surfaces immediately after extraction. Teeth were then immersed for 24 hours in a bath containing 3\% sodium hypochlorite to eliminate residual soft tissues. Following sterilization, each tooth received an ideal access preparation.

\section{Shaping and Filling of the Root Canals:}

After access cavity preparation, working length was set $1 \mathrm{~mm}$ short of the length established visually using size $10 \mathrm{~K}$-file inserted into the root canal until its tip is visible at the apical foramen. A circumferential 'staging platform' was established near the canal orifice, ensuring a uniform working length (WL) in each tooth.

Initial root canal preparation was performed using the ProTaper system according to manufacturer's instructions up to size F3 (Sx, S1, S2, F1, F2, F3). Cleaning and shaping were performed using a modified step-back flare technique. The coronal third was flared with size 1-3 Gates Glidden drills. The shaping sequence was completed using size $35 \mathrm{~K}$-files at the working length. Canals were irrigated in between instrumentation using $5.25 \% \mathrm{NaOCl}$ and $17 \%$ EDTA solution alternatively. Instruments were cleaned after each use; each sequence was used for four canals before being discarded. Canals were dried after instrumentation with paper points and obturated using the cold lateral condensation technique in following fashion.

\section{Root Canal Obturation:}

Either Zinc oxide-eugenol (ZOE) based sealer, AH Plus sealer or and EndoRez sealer was used. All canals were obturated using gutta-percha and either one of these sealers by cold lateral condensation technique. 
The quality of the root canal fillings was confirmed using postoperative radiographs in mesio-distal (MD) and buccolingual (BL) views.

The whole sample was divided into three groups.

Each group ( $n=21)$ obturated using gutta-percha and either of ZOE based sealer, AH Plus sealer or EndoRez sealer.

The coronal section of the canal was filled in with temporary filling material (Cavit). Prepared samples were stored at room temperature.

\section{Retreatment Technique:}

The groups were further divided into three subgroups, $(n=7)$. Each subgroup was treated with different technique for removal of gutta-percha by:

1. Hedström files

2. R-Endo retreatment file.

3. Mtwo retreatment file.

\section{R-Endo retreatment files}

Canal filling material in group-I was removed using the R-Endo system. R-Endo retreatment files were used with in and out motion on the canal walls according to manufacturer's instruction. The Rm stainless steel manual file ( $17 \mathrm{~mm}, 4 \%$ taper) was used first to relocate the canal orifices. It was followed by nickel-titanium rotary instruments Re (size 25, 12\% taper). This instrument removed the first $2-3 \mathrm{~mm}$ of the filling. R1 (size 25, 8\% taper) and R2 (size 25, 6\% taper) were used to one-third and two-thirds of the estimated working length respectively. Finally R3 (size 25, 4\% taper) was used at the working length to complete the removal of filling material from the canal.

\section{MTwo Retreatment Files}

The canal filling in group II was removed using MTwo Retreatment Files. An MTwo R file size 15, 0.05 taper was first used to working length followed by MTwo R size 25 , taper 0.05 also to working length. The normal shaping sequence was then used (e.g. MTwo size 30, taper 0.05; size 35, taper 0.04 and size 40, taper 0.04). Progression of the rotary files was performed by applying pressure and frequently removing the files to inspect the blades and clean the debris.

\section{Hedström files}

Removal of the root canal filling material was begun with the use of sizes1-3 Gates Glidden drills in the coronal portion. With gutta-percha solvent (Endosolv), Hedström files sized 35, 30 and 25 were used in circumferential motion to remove the root filling material from the middle and apical portions until the original working length had been reached.

Roots were split longitudinally with carborundom disk and cut into two halves with the help of chisel and mallet and photographed under stereomicroscope. The pictures were analyzed using an image analysis software program (Digimizer Copyright Version 4.1 ? 2005-2012 MedCalc Software) to determine the area of remaining obturation material. The residual guttapercha was calculated for the whole canal as well as for the coronal, middle and apical thirds.

The ratio between root canal wall area covered by the remnants of gutta-percha and sealer and the total root canal area was then calculated and expressed as a percentage. The mean distribution of gutta-percha within the three groups was also calculated.

\section{Time Required for Gutta-percha Removal:}

The operating time which elapsed from initial guttapercha removal with the first instrument until reaching the original working length was recorded as T1. The time required to achieve satisfactory gutta-percha removal after reaching the working length was recorded as T2. Total time for the procedure was the sum of $\mathrm{T} 1$ and $\mathrm{T} 2$ and was recorded for each group.

\section{STATISTICALANALYSIS}

Analysis of variance (ANOVA) was used to analysis the difference in the percentages of gutta-percha and sealer remnants covered area amongst the three groups. One-way ANOVA was applied to compare the operating time amongst the three groups. Tukey's honestly significant difference test was performed as the post hoc multiple comparison method. The level of significance in all tests was set at $p<0.05$.

\section{RESULTS}

\section{Gutta-percha removal}

When considering the root canal in its entirety no significant differences between the material removal ability of the M-Two and R-Endo systems were 
observed. When compared with the manual technique, however, both systems were more effective in removing filling material from the root canal walls $(\mathrm{P}<$ $0.05)$. There was no significant difference between systems regarding the coronal third. However, differences were significant in the middle and apical third $(\mathrm{P}<0.05)$ with the $\mathrm{R}$-Endo

leaving less debris on root canal walls than the other two systems and the M Two being significantly more effective $(\mathrm{P}<0.05)$ than manual techniques for removing filling material.

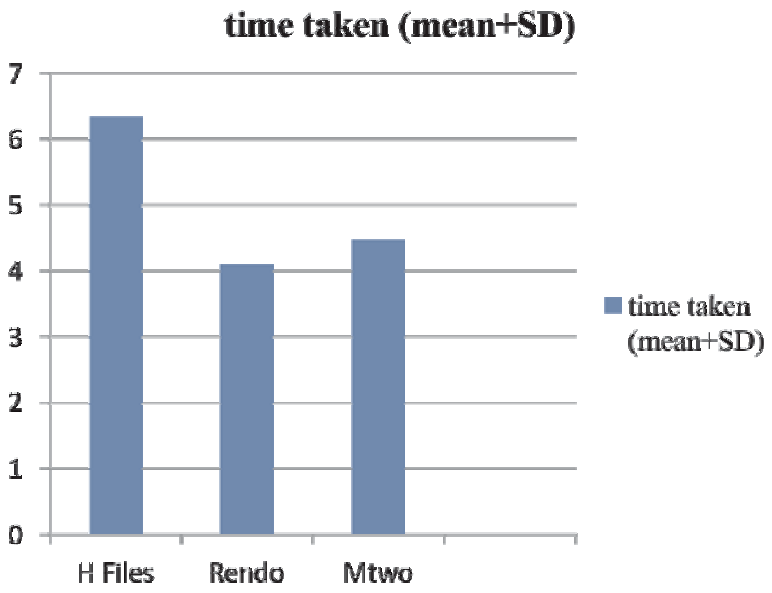

Graph-1. Bar graph showing mean time for retreatment.

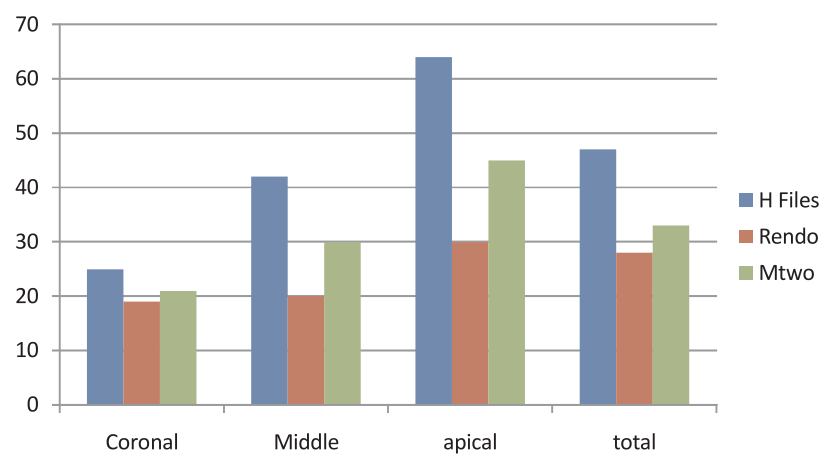

Graph 2 Bar graph showing GP/sealer remnants after retreatment at total root canal coronal, middle and apical level among three groups.

\section{Time required for gutta-percha removal}

The nickel-titanium rotary systems were significantly faster than the control group. There was no significant difference between Mtwo instruments and R-Endo instruments in removing gutta-percha from root canals.

\section{DISCUSSION}

In recent years, significant refinements in the delivery of endodontic services have increased both professional and public expectations for the successful retention of the natural dentition. Along with the salvation of those many millions of teeth every year comes the inevitable percentage of non-healed and unsuccessful treatments. ${ }^{24}$ In 1986, late Dr Herbert Schilder quoted the term "RETREATODONTICS" and said that the future of endodontics lies in the "Retreatment of Endodontic Failures". When root canal therapy fails, treatment options include conventional retreatment, periradicular surgery or extraction. Whenever possible, the retreatment option is preferred because it is the most conservative method to solve the problem. ${ }^{25}$

Rotary NiTi (Nickel Titanium) instruments have also been proposed for the removal of filling materials from the root canal walls and various studies have reported their efficacy, cleaning ability and safety., ${ }^{9,11}$ An epidemiological study showed that most endodontic clinical failures requiring nonsurgical retreatment, apical surgery or extraction were recognized with in the first 3 years. ${ }^{26}$ The success rate of endodontic retreatment ranges from $56-84 \%{ }^{24}$ Although there was no statistically significant difference between the success rate of surgery and for conventional retreatment the preferred treatment of failing endodontic cases is non surgical retreatment. ${ }^{27}$ Surgical retreatment resulted in more postoperative discomfort. ${ }^{28}$ The success of retreatment depends on alterations in the natural course of root canals caused by previous treatment ${ }^{29}$ and procedural errors. ${ }^{24}$ Preoperative perforations, root filling quality, quality of post operative restorations and apical periodontitis are strong predictors for the outcome of endodontic retreatment. Higher success rates can be achieved if the root canal space has been adequately addressed prior to surgical intervention. ${ }^{24} \mathrm{~A}$ growing interest in endodontic retreatment has been seen recently, caused by an increasing demand to preserve teeth, including those cases where endodontic therapy had failed. ${ }^{25}$ Complete removal of pre-existing filling material from the canal can uncover residual necrotic tissues or 
bacteria that may be responsible for persistent periapical inflammation, and allow further cleaning and refilling of the root canal system., ${ }^{8,13}$

The objective of this study was to evaluate and compare the debridement in-vitro efficacy of the NI-TI retreatment systems and hand files for removing guttapercha from root canals filled with three different types of sealers. The study showed presence of residual filling material in almost the entire samples post instrument to remove obturation. Complete removal was achieved in few teeth, but this was not statistically significant. The complete removal in some samples is consistent with other reports. This study used vertical splitting to obtain images for observation after retreatment. Vertical splitting is a well-established method to obtain images of the root halves, using a stereomicroscope at 6X magnification. This method offers advantages over other techniques because it is easy to use and the distance between surface of the object and the device is constant, thus enabling image standardization.

Over the years, nonsurgical endodontic retreatment has replaced surgical endodontic retreatment as the treatment of choice for cases of endodontic therapy failure. ${ }^{30}$ Removal of filling material is an important factor in root canal retreatment. Thus, the maximum quantity of obturation material should be removed $^{11}$. A major goal of root canal retreatment is removal of filling material. This allows effective action of instruments and irrigating solutions on debris and microorganisms responsible for apical periodontitis. However, complete removal of filling material is challenging.

Different methods have been applied to remove root canal filling material from canals. These include use of hand files, ultrasonic files, engine driven instruments and lasers. ${ }^{9,31}$ Conventional removal of gutta-percha using hand files with or without solvent can be a tedious and time consuming process, especially when the root filling material is well condensed. $^{23}$ Therefore the use of rotary NiTi instruments in root canal retreatment might decrease patient and operator fatigue. In the presence of endodontic failure, a nonsurgical approach to the root canal system is preferable to a surgical procedure, even if there is no evidence of a statistically significantly better prognosis. ${ }^{32}$ The literature reports variable success percentages for retreatment ranging from $40 \%-100 \%{ }^{27}$; the variability of the outcome in endodontic retreatment is related to different factors: patient age and the types of teeth treated ${ }^{33}$, the presence of alterations in the natural course of the root canals ${ }^{29}$, the possibility of removing the coronal restorations to access the pulp chamber ${ }^{31}$, the techniques used to remove the existing filling materials, and the possibility of repairing pathologic or iatrogenic defects. ${ }^{34}$

In a previous study ${ }^{35}$, a different method was used to assess the cleaning of the canal walls. In present study the teeth were split longitudinally, and residual gutta-percha and sealer were measured linearly. This is not necessarily the best or the most precise method, but it minimizes subjectivity with respect to the use of a scoring system based on scales. ${ }^{36,37,8}$ The average score of one experimental group does not always reflect the original data. Moreover, microcomputer tomography ${ }^{38}$, micro radiographic technique, and transparent teeth methods represent the most valuable techniques for the qualitative and quantitative evaluation of retreatment procedures. Ideally, three-dimensional visualization of the root canal system would provide a better understanding of the distribution of the debris after retreatment. ${ }^{23,38}$

Recently, Ni-Ti instruments specially designed for removal of filling materials have been marketed, including MTwo Retreatment Files (Sweden \& Martina, Padova, Italia) and R-Endo (Micro-Mega). This study was set out to evaluate radiographically the effectiveness of these instruments in removing guttapercha and sealer. The introduction of NiTi instruments ${ }^{15}$ and the use of solvent ${ }^{39}$ have been reported to decrease the time required to remove gutta-percha and sealer. A drop of solvent containing tetrachloroethylene (Endosolv E) was used at the beginning of the retreatment procedure for two minute to soften the coronal filling material to improve the penetration of the files and to avoid the formation of a film of guttapercha on the canal walls as observed when chloroform was used ${ }^{40}$. 
In the current study, all retreatment techniques left $\mathrm{GP} /$ sealer remnants within the root canal. This finding confirms previous results reported by numerous investigators using different retreatment instruments, techniques and solvents. Furthermore, the present investigation showed that rotary NiTi instruments, the R-Endo and Mtwo instrumentation was significantly more effective than and Hedstrom group in terms of residual material, whereas no statistical difference was found amongst the R-Endo and Mtwo instrumentation group.

In the current study, when comparing the two Ni-Ti techniques, no statistically significant differences were found in the whole root canal and in the coronal third, while in the middle and apical third; the R-Endo gave better results. This can be explained by the fact that the system uses a crown-down approach, while M-Two retreatment files tend to immediately reach the working length. The crown-down approach eliminates the filling material from the coronal third, and this may be why instrumentation was more effective in the apical and middle thirds and for R-Endo instruments produced fewer cases of apical extrusion.

The manufacturer of R-Endo instruments claims that instrument is designed especially for retreatment are machined into a round blank and they have a triangular cross-section with three equally spaced cutting edges; the instrument has neither radial land nor an active tip. This system has sufficient rigidity to remove material from the root canal.

The Mtwo instruments have an S-shaped cross section, an increasing pitch length in the apical coronal direction and characterized by positive rake angle with two cutting edges, which are claimed to cut dentin effectively. ${ }^{41}$ Unlike other NiTi instruments, the Mtwo rotary instruments do not require a crown-down instrumentation sequence. Using the Mtwo instruments with the single length preparation leaves more filling material in the canal during retreatment.

In the current study statistical tests revealed that, with the exception of the coronal third, nickel-titanium instruments were more effective at removing guttapercha from the root canal when compared with the hand instruments. Many reports have concluded that
$\mathrm{Ni}$-Ti instruments are no better than hand files. Indeed, Betti \& Bramante $(2001)^{39}$ claimed that hand files were more efficient in the coronal third. However, Masiero \& Barletta (2005) reported that K3 Endo System (SybronEndo) was more efficient than hand files in the apical third. In this study, greater effectiveness of Ni-Ti instruments was found: this may be due to the fact that these instruments were designed specifically for removing material. The fact that no statistically significant differences were found in the coronal third may be due to the use of GG burs that are known to be effective in this area.

The coronal part of the each root canal was prepared by GG to make an easier removal of root canal filling. In some of the studies, the solvents have been used with the instruments to remove of root canal filling. ${ }^{15}$ Hülsmann \& Bluhm ${ }^{16}$ indicated that no significant difference between removing gutta-percha with and without solvent regarding time required for retreatment using rotary and Hedström files. According to Wilcox, the use of Hedström file without a solvent is more time consuming than other techniques. ${ }^{12}$ On the other hand, some studies reported that the removal of the filling material by using solvents was difficult because the fine layer of softened gutta-percha was formed and adhered to the root canal walls.

In this study, we used two resin based sealers, epoxy resin sealer AH plus, methacrylate based sealer EndoRez and Zinc oxide-containing sealer which are accepted as the golden standard in the literature of endodontics research used. When the roots filled with these sealers were examined considering the total amount of remaining root canal filling material, there was no statistically difference found between the removal techniques. On the other hand, the maximum remaining material was seen in group 2 filled with $\mathrm{AH}$ plus with Hedström files retreatment file.

In the literature, there are comparative studies relating to the amount of filling residue in the root canal after retreatment. ${ }^{42,15,43}$ It was reported that the removal techniques were not different from each other in terms of their removal ability, and all instruments left remnants of filling material and debris on the root canal 
walls. ${ }^{8,20,21}$ However, rotary instrumentation has been shown to be more effective than Hedstrom files in removing gutta-percha from root canal. ${ }^{15,8}$ Similar results were obtained by the present study that demonstrated the efficacy of R Endo and Mtwo compared with Hedstrom file.

When the time consumed for the removal of the used filling material, similar results were obtained in groups sealed with EndoRez and AH plus sealer. The shortest time was recorded in R-Endo retreatment file groups used for removal of the filling materials. On the other hand, regardless of the filling technique and material, the maximum time consumed for removal of filling materials was obtained by Hedstrom file in all groups. A possible explanation could be that Mtwo and $\mathrm{R}$-Endo retreatment files were used in rotational motion, whereas Hedstrom file in the all groups was used in push-pull filing action. It is believed that the rotary motion of Mtwo and R-Endo retreatment file plasticizes the gutta-percha by heat thus it is easier to remove the material. Furthermore, specific flute design of this file tends to pull gutta-percha into the file flutes. Similarly, some of the previous studies indicated that the rotary files required less time for retreatment compared to Hedström files. ${ }^{15,4}$ According to Hulsmann \& Bluhm, ProTaper retreatment files frequently removed large amounts of gutta-percha in spirals around the instruments, whereas Hedström files mainly removed the gutta-percha in small increments that did not adhere to the instruments. ${ }^{15}$ It may be one of the answers to the question of "why a lot of time was consumed with the Hedström file?"

The remaining filling material after removal of Zinc oxide-containing sealers was significantly less when compared with the other groups. That might be due to the fact that Zinc oxide-containing sealers do not exhibit chemical bonding to the canal wall and frequently "peeled off" the canal during retreatment. In the gutta-percha with Zinc oxide-containing sealers there was no chemical bonding between gutta-percha and the sealer ${ }^{44}$. Resin-based obturation systems are emerging as promising alternatives to gutta-percha because of their acclaimed superiority ${ }^{45}$. This should be investigated in all aspects of root canal treatment including retreatment, because no obturation system as yet claims to have a $100 \%$ success rate. Advantages of these new systems include increased resistance to vertical fracture ${ }^{46,21,47}$ and minimal leakage. ${ }^{48,49}$ Disadvantages include polymerization shrinkage ${ }^{50}$ and susceptibility to biodegradation.

In the present study we found that when considering the root canal in its entirety no significant differences between the material removal ability of the M-Two and R-Endo systems were observed. When compared with the manual technique, however, both systems were more effective in removing filling material from the root canal walls $(\mathrm{P}<0.05)$. There was no significant difference between systems regarding the coronal third. However, differences were significant in the middle and apical third $(\mathrm{P}<0.05)$ with the R-Endo leaving less debris on root canal walls than the other two systems and the $\mathrm{M}$ Two being significantly more effective $(\mathrm{P}<0.05)$ than manual techniques for removing filling material.

\section{CONCLUSION}

Within the parameters of this study, the following conclusions may be drawn:

- None of the techniques removed all filling materials from root canal walls.

- R-Endo retreatment files left significantly less gutta-percha and sealer than Mtwo system and Hedstrom files.

- Re-treatment with R-Endo and Mtwo retreatment NiTi rotary systems was significantly faster than manual instrumentation in the removal of guttapercha/ sealer.

- When the roots filled with these sealers were examined, there was no statistically difference found between the removal techniques. The maximum remaining material was seen in teeth filled with $\mathrm{AH}$ plus with Hedström files retreatment file.

\section{REFERENCES}

1. Douglas A Terry. Direct applications of a nanocomposite resin system: Part I - The evolution of contemporary composite materials. Pract ProcedAesthet Dent 2004;16(6):418. 
2. Turkun LS, Aktener BO, Ates M. Clinical evalutation of different posterior resin composite materials: A 7-year report. Quint Int 2003;34:418-426.

3. Herrero AA, Yaman P, Dennison JB. Polymerization shrinkage and depth of cure of packable composites. Quint Int 2005;36:25-31.

4. Mitra SB, Wu D, Holmes BN. An application of nanotechnology on advanced dental materials. J Am Dent Assoc. 2003;134:1382-1390.

5. Gupta S, Khinda VIS, Grewal N. A Comparative study of Microleakage below Cemento-enameljunction using Light Cure and Chemically Cured glass lonomer cement liners. J Indian Soc Pedo Prev Dent December 2002; 20(4):158-184.

6. Bayne SC, Thompson JY, Swift EJ, Jr, Stamatiades P, Wilkerson P. A characterization of first generation flowable composites. JAm Dent Assoc. 1998;129:567-577.

7. Attar N, Tam LE, McComb D. Flow, strength, stiffness and radioopacity of flowable resin composites. J Can Dent Assoc. 2003; 61:516-521.

8. Cobb DS, Macgregor KM, Vargas MA, and Denehy GE. The physical properties of packable and conventional posterior resin-based composites: a comparison. J Am Dent Assoc 2000; 131:1610-1615.

9. Hickel R and Manhart J. Longevity of restorations in posterior teeth and reasons for failure. J Adhes Dent 2001; 3:45-64.

10. Peutzfeldt A. Resin composites in dentistry: the monomer systems. Eur J Oral Sci 1997; 105:97-116.

11. Sheth JJ, Jensen ME, Sheth PJ, Versteeg J. Effect of etching glassionomer cements on bond strength to composite resin. J Dent Res 1989; 68:1082-7.

12. Arora V, Kundabala M, Parolia A, Thomas MS, Pai V. Comparison of the shear bond strength of RMGIC to a resin composite using different adhesive systems: An invitro study. J Conserv Dent 2010;13:80-3.

13. Liebenberg WH. Successive cusp build-up: an improved placement technique for posterior direct resin restorations. J Can Dent Assoc 1996;62:501-7.

14. Yazici RA, Celik C, Ozgunaltay G. Microleakage of different resin composite types. Quint Int 2004; 23(10):790-794.

15. Van Meerbeek B, Willens G, Celis JP, Roos JR, Lambrechts $P$, Vanherle G. Assessment by nanoindentation of the hardness and elasticity of the resin-dentin bonding area. J Dent Res 1993; 72:1434-1442.

16. Owens BM (2002). The effect of different drying methods for single step adhesive systems on microleakage of tooth colored restorations J Contemp Dent Pract 3(4):1-10.

17. Sidhu SK, Henderson LJ. In vitro marginal leakage of cervical composite resins restorations lined with a light-cured glass ionomer. Oper Dent 1992;17:7-12.

18. Aboushala A, Kugel G, Hurley E. Class II composite resin restorations using glass- ionomer liners: Microleakage studies. J Clin Pediatr Dent 1996;21:67-70.
19. Tollidos K, Setcos JC. Initial degree of polymerization shrinkage exhibited by flowable composite resins. J Dent Res 1999;78:483-5.

20. Tredwin CJ, Stokes A, Moles DR. Influence of flowable liners and margin location on microleakage of conventional and packable class II resin composites. Oper Dent 2005;30:32-8.

21. Chuang SF, Jin YT, Liu JK, Chang CH, Shieh DB. Influence of flowable lining thickness on class II composite restorations. Oper Dent 2004;29:301-8.

22. Derhami K, Colli P, Brannstrom M. Microleakage in Class 2 composite restorations. Oper Dent 1995;20:100-5.

23. Demarco FF, Ramos OL, Mota CS, Formolo E, Justino ML. Influence of different restorative techniques on microleakage in class II cavities with gingival wall in cementum. Oper Dent 2001;26:253-9.

24. Ingle JI, Bakland LK, Baumgartner CJ. Ingles Endodontics 6 . 6th edition. Hamilton: BC Decker Inc; 2008.

25. Lovdahl PE. Endodontic Retreatment. Dent Clin North Am 1992; 36:473-490.

26. Salehrabi R and Rotstein I. Endodontic treatment outcomes in a large patient population in the USA: an epidemiological study. J Endod 2004; 30:846-850.

27. Paik S, Sechrist C, Torabinejad M. Levels of evidence for the outcome of endodontic retreatment. J Endod 2004; 30:745750 .

28. Kvist T, Reit C. Postoperative discomfort associated with surgical and nonsurgical endodontic retreatment. Endod Dent Traumatol 2000; 16:71-74.

29. Gorni FG, Gagliani MM. The outcome of endodontic retreatment: a 2-yr follow-up. J Endod 2004; 30:1-4.

30. Barletta FB, Rahde Nde M, Limongi O, Moura AA, Zanesco $\mathrm{C}$, Mazocatto $\mathrm{G}$. In vitro comparative analysis of 2 mechanical techniques for removing gutta-percha during retreatment. J Can Dent Assoc 2007; 73:65.

31. Ruddle CJ. Nonsurgical retreatment. In: Cohen S, Burns RC, eds. Pathways of the pulp (ed 8). St Louis, MO: CV Mosby; 2002:875-930.

32. Viduèiae D, Jukiae S, Karloviae Z, Boiae, Miletiae I, Aniae I. Removal of gutta-percha from root canals using an Nd:YAG laser. Int Endod J 2003; 36:670 -673.

33. Imura N, Pinheiro ET, Gomes BP, Zaia AA, Ferraz CC, SouzaFilho FJ. The outcome of endodontic treatment: a retrospective study of 2000 cases performed by a specialist. J Endod 2007; 33:1278-1282.

34. Tronstad L, Niemczyk SP. Efficacy and safety tests of six automated devices for root canal instrumentation. Endod Dent Traumatol 1986; 2:270-276.

35. Gu LS, Ling JQ, Wei X, Huang XY. Efficacy of ProTaper Universal rotary retreatment system for gutta-percha removal from root canals. Int Endod J 2008; 41, 288-295.

36. Tasdemir T, Yildirim T, Celik D. Comparative study of removal of current endodontic fillings. J Endod 2008; 34:326 -329 . 
37. Ferreira JJ, Rhodes JS, Ford TR. The efficacy of gutta-percha removal using ProFiles. Int Endod J 2001; 34:267-274.

38. Rhodes JS, Ford TR, Lynch JA, Liepins PJ, Curtis RV. Microcomputed tomography: a new tool for experimental endodontology. Int Endod J 1999; 32:165-170.

39. Betti LV, Bramante CM. Quantec SX rotary instruments versus hand files for gutta-percha removal in root canal retreatment. Int Endod J 2001; 34, 514-519.

40. Sae-Lim V, Rajamanickam I, Lim BK, Lee HL. Effectiveness of Profile.04 taper rotary instruments in endodontic retreatment. J Endod 2000; 26:100-104.

41. Schafer E, Erler M, Dammaschke T. Comparative study on the shaping ability and cleaning efficiency of rotary Mtwo instruments. Part1. Shaping ability in simulated curved root canals. Int Endod J 2006; 39: 196-202.

42. Tachinami H, Katsuumi I. Removal of root canal filling materials using Er: YAG laser irradiation. Dent Mater J 2010; 29:246-252.

43. Valois CR, Navarro M, Ramos AA, de Castro AJ, Gahyva SM. Effectiveness of the ProFile .04 taper series 29 files in removal of gutta-percha root fillings during curved root canal retreatment. Braz Dent J 2001; 12: 95-99.

44. Schirrmeister JF, Meyer KM, Hermanns P, Altenburger MJ, Wrbas KT. Effectiveness of hand and rotary instrumentation for removing a new synthetic polymer-based root canal obturation material (Epiphany) during retreatment. Int Endod J 2006; 39: 150-156.

45. Ezzie E, Fleury A, Solomon E, Spears R, He J. Efficacy of retreatment techniques for a resin-based root canal obturation material. J Endod 2006; 32:341-344.

46. de Oliveira DP, Barbizam JV, Trope M, Teixeira FB. Comparison between gutta-percha and resilon removal using two different techniques in endodontic retreatment. J Endod 2006; 32, 362-364.

47. Schafer E, Zandbiglari T, Schafer J. Influence of resin-based adhesive root canal fillings on the resistance to fracture of endodontically treated roots: an in vitro preliminary study. Oral Surg Oral Med Oral Pathol Oral Radiol Endod 2007; 103:274-279.

48. Shipper G, Orstavik D, Teixeira FB, Trope M. An evaluation of microbial leakage in roots filled with a thermoplastic synthetic polymer-based root canal filling material (Resilon). J Endod 2004; 30:342-347.

49. Aptekar A, Ginnan K. Comparative analysis of microleakage and seal for 2 obturation materials: Resilon/Epiphany and gutta-percha. J Can Dent Assoc 2006; 72:245.

50. Tay FR, Pashley DH, Yiu CK. Susceptibility of a polycaprolactone-based root canal filling material to degradation: II-gravimetric evaluation of enzymatic hydrolysis. J Endod 2005; 31:737-741. 